\title{
Personality, Coping Strategy, and Quality of Life of Patients with Chronic Kidney Disease
}

\author{
Evlijn Pasha Widjast ${ }^{* 1}$, Magdalena S Halim ${ }^{2}$ \\ ${ }^{1,2}$ Faculty of Psychology, Atma Jaya Catholic University of Indonesia
}

Submission 6 August 2018 Accepted 4 August 2021 Published 24 December 2021

\begin{abstract}
Patients with chronic kidney disease are subject to prolonged medical treatment that might affect their quality of life. The purpose of this research was to investigate the correlation between personality, coping strategies, and quality of life in patients with chronic kidney disease. 40 Participants (25-55 years old) were recruited using purposive sampling and presented with three instruments: the Indonesian versions of NEO Personality Inventory-Revised (NEO PI-R), Ways of Copings, and Kidney Disease Quality of Life-36 (KDQOL-36). Results showed a significant correlation between all variables after regression analysis was applied. Further results indicate certain coping strategies were related to an individual's perceptions of kidney disease. A significant correlation was found between three personality traits: neuroticism, extraversion and conscientiousness, and quality of life. Results also found that female patients have a better quality of life than men. Further research is needed to examine further the crucial role of social support and ethnic differences. Psychological intervention programs to provide psychoeducation on how to recognize stress symptoms and better stress management for patients with chronic kidney disease are also warranted.
\end{abstract}

Keywords: coping strategy; chronic kidney disease; personality; quality of life

Chronic kidney disease prevalence in Indonesia is steadily increasing and aligns with the global trend. Data from the Basic Health Research Report from the Ministry of Health (2018) showed an increase of prevalence of patients with chronic kidney disease from $0.2 \%$ in 2013 to $0.38 \%$ in 2018 . Chronic kidney disease is a pathophysiological process with various aetiologies that results in a progressive, chronic and generally irreversible decline in kidney function, characterized by high levels of urea and serum creatinine and if not treated immediately will result in death. Stage 5 is also called end-stage renal disease (PGTA)/End Stage Renal Disease (ESRD) which requires permanent kidney replacement therapy, in the form of hemodialysis or kidney transplantation (Saswita \& Bayhakki., 2015). As such, special attention is required to provide more effective comprehensive treatment both medically and psychosocially.

Researchers have studied physical and psychological changes experienced by patients with chronic kidney disease. Niven (2002) stated that lifelong hemodialysis treatment and medication, diet, fluid restriction and adjustment to the disease experienced can lead to changes in the patient's life. Physical changes felt by the patient, such as nausea, chills, vomiting, headache, insomnia, back pain,

*Address for correspondence: evlijnpw@gmail.com 
hypotension, and itching disrupt individuals' physical functioning, which might limit social activities. Patients often must stop working when they are diagnosed with chronic kidney disease (Niven, 2002).

Quality of life is one indicator of the success of hemodialysis therapy and is associated with the risk of kidney disease development and, further, the risk of death (Mailani, 2015). This means that the quality of life of patients with chronic kidney disease will have an impact on the progress of the disease they are experiencing. Interference of quality of life will worsen the patient's health condition and result in a more fatal risk, death. As such, it is crucial to study the quality of life of chronic kidney disease patients, of which is useful to form evidence-based action to improve quality of life of chronic disease patients who are undergoing hemodialysis.

This study assumed that patients with chronic kidney disease who must undergo renal replacement therapy for their entire life will tend to have a poor quality of life because the therapy process has an impact on all aspects of their lives such as on the physical aspects, such as itching, dry skin, nausea, on aspects of life; psychological aspects such as feelings of hopelessness, sadness, depression, and also on the social aspects such as loss of work and reduced social activities.

This study aimed to determine the relationship between personality and coping strategies with the quality of life of patients with chronic kidney disease. There were four hypotheses in this study.

1. There is a significant relationship between personality and quality of life in patients with chronic kidney disease.

2. There is a significant relationship between coping strategies and quality of life in patients with chronic kidney disease.

3. There is a significant relationship between personality and coping strategy in patients with chronic kidney disease.

4. There is a significant relationship between coping strategy and personality with and quality of life in patients with chronic kidney disease.

\section{Literature review}

Mailani (2015) revealed that the factors affecting quality of life of chronic kidney disease patients undergoing hemodialysis include socio-demographic factors such as gender, age, education level, marital status, employment status or economic status. Earlier studies (Marques, 2014) had also shown that patients undergoing hemodialysis, especially women, tend to have a lower quality of life than men. Hudson in (Priyanti \& Farhana, 2016) stated that work can be a great social support and having an employment status will contribute to quality of life and boost self-confidence.

Several factors that affect the quality of life of patients with chronic renal failure are also related to the individual's response to the changes that occur in their life. Humans have a unique way of adapting to changes in their lives. The individual's distinctive way of adapting to the environment 
is also called personality. The response from one individual to another is different when facing the pressure of chronic kidney disease. Personality can also affect the quality of life of patients with chronic kidney disease (Bakhtiari et al., 2013).

Chan et al. (2011) suggested that personality traits and cognitive evaluation have a strong relationship with the incidence of depression in end-stage renal disease (ESRD) patients. The correlation also depends on gender, age and type of dialysis. Depression is generally experienced in patients with kidney failure stage III and above with 3 to 9 years of treatment for kidney failure. This is also experienced by female patients rather than male. Symptoms that appear are usually feelings of sadness, anxiety, depression, low self-esteem, pessimism about the future and lack of appetite. Therefore, the personality traits possessed by chronic kidney disease patients may lead them to use specific responses in dealing with stressors in the form of chronic kidney disease that arise in their lives so that it will affect their perception of the resources they have to deal with stress and affect their quality of life.

Several studies (Bakhtiari et al., 2013; Poppe et al., 2012; van Straten et al., 2006) found that neuroticism has a negative relationship to quality of life. It means that if an individual has high neuroticism, the quality of life tends to be below. Whereas, poor quality of life is closely related to the risk of death in patients with kidney failure. Research conducted by Turiano et al. (2012) suggested that people with high extraversion traits tend to engage in active coping and prefer external stimulation so that they can be easily diverted from their disability.

Other studies have stated that there is a positive relationship between Agreeableness, Extraversion and Conscientiousness with quality of life and individual health (Bakhtiari et al., 2013; Cellar et al., 2016; Roberts et al., 2005; Turiano et al., 2012). Extraversion is associated with positive affect and a better quality of life because individuals with high extraversion spend more time interacting socially (Steel et al., 2008) and prefer external stimulation so they are easily distracted from their problems. Conscientiousness is also related to the attitude of adherence to treatment to improve the patient's quality of life (Turiano et al., 2012). These findings suggest the need for a psychological evaluation of the personality characteristics of patients with chronic kidney disease to recognize and deal with these psychological aspects related to quality of life and further interventions.

When patients with chronic kidney disease meet the demands of the disease they are having, they can experience stress or a gap that is determined by the demands of the environment and their own resources. The stress causes physical and mental tension so that individuals try to reduce the discomfort. Coping is an individual process to manage current demands and the resources existing within them that are used in dealing with stressful situations (Sarafino \& Smith, 2012). According to Ana (1999) coping is the way individuals do in solving problems, adapting to changes, and responding to threatening situations.

Lazarus and Folkman in (Sarafino, 2008) revealed that coping in a terminal illness involves dynamic interactions between individuals and their environment. Individuals who seek to change their lifestyle will receive encouragement and good relationships with doctors and their families. In contrast, individuals who ignore their problems are likely to experience poorer health and social 
relationships. Coping can be presented in two main functions Lazarus \& Folkman, in (Sarafino, 2008) which are changing the problems that cause stress (problem-focused coping) or regulating emotional responses to these problems (emotion-focused coping).

Facing stressful situations, individuals who experience chronic diseases will feel tension which makes individuals try to reduce the discomfort with certain coping strategies. Coping strategies that are less effective will make the stress improperly handled so that eventually it will reduce the quality of life of patients with chronic kidney disease. The way they view their health on certain personality traits to stress can lead to a tendency to use ineffective strategies in managing stress that have an impact on their quality of life.

\section{Method}

\section{Participants}

The participants of this study were end-stage chronic kidney disease patients undergoing treatment (outpatient) at a hospital located in Jakarta, who were recruited purposively, with the following criteria:

(1) using BPJS health services and had undergone hemodialysis for at least three months; (2) able to read and write (at least a junior high school graduate); (3) were willing to be participants in this study, and (4) participants were not experiencing severe physical symptoms before or in the midst of data collection, for example, an unwell body condition to undergo research procedures, and so on.

The process of participants recruitment collaborated with ward nurses where participants were registered as outpatients in the hemodialysis unit. The ward nurse selected participants based on medical records data and professional judgment. There were 40 participants who met the criteria and were willing to take part in the study. The demographics of the participants are presented in Table 1. Consent was sought by explaining the purpose, limitations of the study, research process, and the rights of the research participants. All 40 participants provided written consent to participate in the study.

Table 1

Demographic Data of Research Participants

\begin{tabular}{llll}
\hline Personal information & & Frequency & Percentage \\
\hline \multirow{2}{*}{ Gender } & Man & 21 & $52.5 \%$ \\
& Woman & 19 & $47.5 \%$ \\
\hline \multirow{2}{*}{ Age } & Early Adulthood (25-40 year-old) & 18 & $45 \%$ \\
& Middle Adulthood (41-55 & 22 & $55 \%$ \\
& year-old) & & \\
\hline \multirow{2}{*}{ Marital Status } & Single & 4 & $10 \%$ \\
& Married & 36 & $90 \%$ \\
\hline Education & Middle-Senior High School & 21 & $52.5 \%$
\end{tabular}




\begin{tabular}{|c|c|c|c|}
\hline & Diploma-Undergraduate & 19 & $47.5 \%$ \\
\hline \multirow[t]{2}{*}{ Work } & Employed & 25 & $62.5 \%$ \\
\hline & Unemployed & 15 & $37.5 \%$ \\
\hline \multirow[t]{2}{*}{$\begin{array}{l}\text { Chronic Kidney Disease } \\
\text { Period }\end{array}$} & $<5$ years & 28 & $76 \%$ \\
\hline & $>5$ years & 12 & $30 \%$ \\
\hline \multirow[t]{2}{*}{ Hemodialysis History } & Never undergo hemodialysis & 17 & $42.5 \%$ \\
\hline & Regular hemodialysis treatment & 23 & $57.5 \%$ \\
\hline \multirow[t]{2}{*}{$\begin{array}{l}\text { Comorbidity } \\
\text { (Hypertension, } \\
\text { Diabetics, Lupus) }\end{array}$} & Yes & 31 & $77.5 \%$ \\
\hline & No & 9 & $22.5 \%$ \\
\hline \multirow[t]{2}{*}{ Hemodialysis Procedures } & Twice a week & 35 & $87.5 \%$ \\
\hline & Three times a week & 5 & $12.5 \%$ \\
\hline
\end{tabular}

\section{Data collection}

This study adopted quantitative correlational research. The correlational research design is commonly used to investigate the relationship between two or more variables to understand the level and pattern of the relationship between variables. This design is suitable for this research and was used to investigate the relationship between personality, coping strategy and quality of life. Data collection was carried out by first explaining in advance to participants about the aims and objectives of the study, followed by presenting the data collection instruments.

There were three standardized self-report questionnaires used in this study, these were namely NEO Personality Inventory-Revised (NEO PI-R), Ways of Coping and Kidney Disease Quality of Life-36 (KDQOL-36). Each of the instruments is described in turn.

1. Kidney Disease Quality of Life-36 (KDQOL-36) Indonesian version

The Kidney Disease Quality of Life-36 (KDQOL-36) is derived from KDQOL (The Kidney Disease Quality of Life) developed by Hays, Kallich, Mapes, Coons and Carter in 1994 (Hays et al., 1997). It is commonly used to measure quality of life for hemodialysis patients. The KDQOL has a reliability range of .78 to .92 in all aspects. KDQOL-36 is also suitable and has been used in research involving dialysis patients on a dialysis treatment for 3 months. Aspects that are measured in KDQOL-36 include physical and mental problems, symptoms (of kidney disease), burden of kidney disease, and effects of kidney disease. KDQOL-36 uses a Likert scale with a score range of 1-5 which will then be converted into a 0-100 scale score. The higher the KDQOL-36 score, the better or higher the quality of life.

2. NEO Personality Inventory-Revised (NEO PI-R)

NEO-PI $\mathrm{R}$ is designed to measure personality dimensions based on the Five Factor Model: Neuroticism, Extraversion, Openness to experience, Agreeableness, and Conscientiousness. This 
questionnaire consists of 240 items that measure the five domains, and is equipped with 6 facets in each domain. NEO-PIR is accompanied by a choice of answers in the form of a Likert scale with a score range of 0-4. The Indonesian version of the NEO PI-R (Halim et al., 2004) was developed based on the Five Factor Personality Model. The results of Cronbach-alpha reliability for each domain in the adaptation of the NEO PI-R test in Indonesian ranging from .75 to .90 (Halim et al., 2004). Meanwhile, the results of internal validity testing using factor analysis on the adaptation of the NEO PI-R test in Indonesian can also be said to be good, with a total variance of $54.56 \%$ and a total congruence ranging from .91 to .96 (Halim et al., 2004).

\section{Ways Of Coping Scale (WSC) Indonesian version}

The Ways of Coping (WSC) questionnaire was developed by Folkman and Lazarus (1985) to measure an individual's coping processes in dealing with certain stressors. This study used the Indonesia adaptation of Ways of Coping-Short Form that consists of 50 statement items measured on a Likert scale. The data collection instrument was found valid with a validity value ranging from .307- .636 and a reliability value of .893 .

\section{Data Analysis}

We used a quantitative method to analyze the data from KDQOL-36, WCS, and NEO-PI R with SPSS Statistic 22.0. Validity test used to correlate the items with a total score for each aspect of Ways Of Coping (content validity) and Reliability of each aspect used Cronbach's alpha. The Pearson product-moment correlation was used to measure the relationship between personality, coping strategy, and each aspect of quality of life. Moreover, Chi-Square was used to observe the relationship between demographic data with quality of life.

\section{Results}

\section{Correlation Test Results}

Table 2 shows the results of the correlation test between personality and quality of life using Pearson Product Moment. Personality (neuroticism and extraversion) was significantly related to the total score of Quality of Life. The results indicated that the higher the neuroticism trait, the lower the quality of life of chronic kidney disease patients undergoing hemodialysis. It can be interpreted that if chronic kidney disease patients have high neuroticism, they will feel more burdened because of the obstacles in their physical activity and emotional condition, the more often they experience disturbances due to common symptoms experienced by hemodialysis patients, it is more difficult to adjust to the impact of dialysis on their lives.

The extraversion personality trait was found to have a significant positive correlation with aspects of quality of life, physical and mental problems ( $r=.370, \mathrm{p}<.05$ with moderate effect size, $\mathrm{r} 2=.136)$ and symptoms $(\mathrm{r}=.330, \mathrm{p}<.05$ with medium effect size, $\mathrm{r} 2=.108)$ and the total score of 
quality of life $(\mathrm{r}=.345, \mathrm{p}<.05$ with moderate effect size, $\mathrm{r} 2=.119)$. A significant positive correlation was also found in the conscientiousness personality trait with aspects of quality of life, symptoms ( $\mathrm{r}=$ $.340, \mathrm{p}<.05$ with moderate effect size, $\mathrm{r} 2=.115$ ). Based on these results, the higher extraversion and conscientiousness traits resulted in fewer disturbances experienced due to the symptoms of chronic kidney disease such as nausea, cramps, pallor, headaches, itchy skin, and so on. High extraversion also means that patients assess their physical and emotional condition as not being an obstacle in their daily work.

Table 2

Correlation between Personality and Quality of Life

\begin{tabular}{|c|c|c|c|c|c|}
\hline \multirow{3}{*}{ Personality domains } & Physical & \multicolumn{2}{|l|}{ Burden } & \multicolumn{2}{|c|}{ Effect of } \\
\hline & and Mental & Kidney & Symptoms & Kidney & KDQoL \\
\hline & Problems & Disease & & Disease & \\
\hline \multirow{2}{*}{ Neuroticism } & $-.352^{*}$ & -.261 & $-.615^{* *}$ & $-.343^{*}$ & $-.471^{* *}$ \\
\hline & $\rho=.026$ & $\rho=.104$ & $\rho=.000$ & $\rho=.030$ & $p=.002$ \\
\hline \multirow{2}{*}{ Extraversion } & $.370^{*}$ & .296 & $.330^{*}$ & .182 & $.345^{*}$ \\
\hline & $\rho=.019$ & $\rho=.063$ & $\rho=.037$ & $\rho=.261$ & $\rho=.029$ \\
\hline Openness & .051 & .233 & .248 & .032 & .146 \\
\hline Experience & $\rho=.752$ & $\rho=.147$ & $\rho=.123$ & $\rho=.843$ & $\rho=.370$ \\
\hline \multirow{2}{*}{ Agreeableness } & .012 & .115 & .136 & .017 & .076 \\
\hline & $\rho=.941$ & $\rho=.479$ & $\rho=.404$ & $\rho=.915$ & $\rho=.643$ \\
\hline \multirow{2}{*}{ Conscientiousness } & .273 & .308 & $.340^{*}$ & .105 & .290 \\
\hline & $\rho=.088$ & $\rho=.053$ & $\rho=.032$ & $\rho=.521$ & $\rho=.069$ \\
\hline
\end{tabular}

**)Significant $\alpha=1 \% \cdot *)$ Significant $\alpha=5 \%$

Table 3 outlines the relationship between coping strategies and quality of life. There was a significant relationship between coping strategies (problem focused coping and emotion focused coping) with aspects of quality of life. Problem focused coping had a significant positive correlation with aspects of quality of life, which are physical and mental problems $(\mathrm{r}=.326, \mathrm{p}<.05$ with effect size, $\mathrm{r} 2=.106)$ and burden of kidney disease $(\mathrm{r}=.349, \mathrm{p}<.05$ with effect size, $\mathrm{r} 2=.121)$. This result means that by dealing with stressors directly, participants can evaluate their physical and emotional conditions more positively. Further, the more problem-focused coping is used, the perceived disturbances due to the impact of chronic kidney disease will decrease. Meanwhile, emotion-focused coping was found to have a positive correlation with the burden of kidney disease $(\mathrm{r}=.325, \mathrm{p}<.05$ with effect size, $\mathrm{r} 2=.105)$. Thus, more frequent use of stress management to prevent, minimize or reduce the distress experienced, the more positive the judgement of the psychological burden of chronic kidney disease. 
Table 3

Correlation between Coping Strategy and Quality of Life

\begin{tabular}{llllll}
\hline $\begin{array}{l}\text { Coping } \\
\text { Strategy }\end{array}$ & $\begin{array}{l}\text { Physical } \\
\text { and Mental } \\
\text { problems }\end{array}$ & $\begin{array}{l}\text { Burden } \\
\text { Kidney Disease }\end{array}$ & $\begin{array}{l}\text { Problem } \\
\text { symptoms }\end{array}$ & $\begin{array}{l}\text { Effect } \\
\text { Kidney }\end{array}$ & Total \\
\hline Problem & $.326^{*}$ & $.349^{*}$ & .210 & .046 & .277 \\
focused & $\rho=.040$ & $\rho=.027$ & $\rho=.194$ & $\rho=.777$ & $\rho=.084$ \\
\hline Emotion & .189 & $.325^{*}$ & 225 & .068 & .223 \\
focused & $\rho=.243$ & $\rho=.041$ & $\rho=.162$ & $\rho=.676$ & $\rho=.167$ \\
\hline
\end{tabular}

${ }^{* *}$ ) Significant $\left.\alpha=1 \% \cdot *\right)$ Significant $\alpha=5 \%$

Table 4 shows that there was a significant correlation between trait extraversion and problem focused coping $(\mathrm{r}=.317, \mathrm{p}<.05$ with effect size, $\mathrm{r} 2=.100)$. In this study, it was found that individuals who are sociable, active, and enthusiastic will often manage stress directly at the source of the stress they face. While the openness to experience trait was significantly positively correlated with both coping strategies, problem-focused coping $(\mathrm{r}=.570, \mathrm{p}<.01$ with effect size, $\mathrm{r} 2=.324)$ and emotion focused coping $(\mathrm{r}=.521, \mathrm{p}<.01$ with effect size, $\mathrm{r} 2=.271)$. The result can be interpreted that the more individuals have a tendency to be creative, have a high curiosity and like various possibilities, the more actively they use any coping to manage the stress they feel.

Table 4

Correlation between Personality and Coping Strategy

\begin{tabular}{lll}
\hline & Problem focused & Emotion focused \\
\hline \multirow{2}{*}{ Neuroticism } & -.085 & .127 \\
& $\rho=.601$ & $\rho=.435$ \\
\hline \multirow{2}{*}{ Extraversion } & $.317^{*}$ & .203 \\
& $\rho=.047$ & $\rho=.210$ \\
\hline \multirow{2}{*}{ OpennessToExperience } & $.570^{* *}$ & $.521^{* *}$ \\
& $\rho=.000$ & $\rho=.001$ \\
\hline \multirow{2}{*}{ Agreeableness } & -.150 & -.153 \\
& $\rho=.356$ & $\rho=.347$ \\
Conscientiousness & .263 & .169 \\
& $\rho=.102$ & $\rho=.297$ \\
\hline
\end{tabular}

$* *)$ Significant $\alpha=1 \% \cdot *)$ Significant $\alpha=5 \%$

Based on the results above, it was found that the correlation between personality and coping strategy on quality of life was $\mathrm{R}=.610$, where Sig.F Change was $.016<.05, \mathrm{R} 2=.360^{*}$. Thus, it can be concluded that there is a significant relationship between personality and coping strategies with quality of life in patients with kidney failure. These results also state that personality and coping strategies are significant contributors to quality of life $\left(\mathrm{R} 2=.360^{*}\right)$. This can be interpreted that personality variables and coping strategies contribute to explain the quality of life of patients with chronic kidney disease by $36 \%$, while the remaining $64 \%$ is explained by other factors. Based on 
regression calculations, coping strategies provide a greater contribution than personality in explaining quality of life.

Table 5

Correlation of Personality and Coping Strategy with Quality of Life

\begin{tabular}{lllll}
\hline $\mathrm{R}$ & $\mathrm{R}$ Square & Adjusted R Square & $\mathrm{F}$ & Sig \\
\hline .600 & .360 & .243 & 2.715 & .016 \\
\hline
\end{tabular}

\section{Discussions}

The study found that there was a significant relationship between personality, coping strategy and quality of life in patients with chronic kidney disease. There is a significant relationship between several personality traits with quality of life. Neuroticism has a significant negative correlation with aspects of quality of life, which are physical and mental problems, symptoms, and effects of kidney disease. This means that if renal disease patients have a high level of neuroticism, they will feel more affected by the limitations in their physical activity and emotional state, they experience the common symptoms experienced by hemodialysis more often and more difficulty to adjust to the impact of dialysis on their lives. This is in line with the research findings of Prihodova et al. in (Poppe et al., 2012) which revealed that individuals with high neuroticism tend to focus on the health problems they have so that it affects the quality of life. Eysenck in (Cellar et al., 2016) mentioned that neuroticism is defined as a personality trait with symptoms of anxiety, depression, and hostility related to emotional instability which is assumed to stimulate the primary nervous system and stress on the physiological aspects resulting in a more severe reaction to environmental stressors. Patients with chronic kidney diseases with a high neuroticism tend to evaluate themselves and their environment negatively and reduce their quality of life.

The extraversion personality trait was found to have a significant positive correlation with aspects of quality of life: physical and mental problems and symptoms. A significant positive correlation was also found in the conscientiousness trait with the aspects of quality of life, which are symptoms. Based on these results, the higher the extraversion and conscientiousness in chronic kidney disease patients, the less disturbances they have due to the physical symptoms of chronic kidney disease such as nausea, cramps, paleness, headache, itchy skin and so on. (Turiano et al., 2012) mentioned that conscientiousness is also related to the attitude of adherence to treatment in the improvement of a patient's quality of life. This study also found that personality traits of patients with chronic kidney disease also affect their quality of life, these are neuroticism, extraversion, and conscientiousness. This finding is in line with several previous studies (Bakhtiari et al., 2013; Chan et al., 2011; Poppe et al., 2012; Steel et al., 2008).

There is a significant relationship between coping strategy and quality of life in which problem focused coping has a significant positive correlation to aspects of quality of life, which are physical 
and mental problems and burden of kidney disease. Meanwhile, emotion-focused coping was found to have a positive correlation with the aspects of quality of life, burden of kidney disease. This means that the more frequent stress is being managed by preventing, minimizing, or reducing the distress, the more positive the evaluation of the psychological burden of chronic kidney disease that the patients have. The more often these two coping methods are used, the quality of life aspects is increased. This means that the more likely the two coping strategies are used, the psychological burden experienced due to chronic kidney diseases are better perceived.

There is a correlation between personality and coping strategy, where the extraversion is positively correlated with problem focused coping. Individuals who are sociable, active, and enthusiastic will tend to manage stress more often by focusing on the stressor itself and the physical impact that accompanies it. This finding is in line with the research of Turiano et al. (2012) which suggested that people with a high extraversion tend to engage in active coping and prefer external stimulation so that they can be easily diverted from their problems. While the openness to experience trait has a significant positive correlation with both coping strategies. This means that the more individuals have a tendency to be creative, have a high curiosity and tend to pursue new endeavors, the more actively they use coping to manage their stress level.

There are contrasting findings between this study and previous studies. Several other studies have stated that there is a positive relationship between agreeableness, extraversion, and conscientiousness with quality of life as well as individual's health (Bakhtiari et al., 2013; Cellar et al., 2016; Roberts et al., 2005; Turiano et al., 2012). However, in this study, there was no relationship between agreeableness and quality of life in patients with chronic kidney disease. Agreeableness is related to caring or a tendency to act altruistically/how to behave towards others. Individuals who have high scores on the agreeableness trait will have characteristics such as gentleness, trust, generosity, and collaborativeness, whereas low scores on this trait will give a tendency to be having a negative judgement towards others, critical, antagonistic, and harsh. Agreeableness, in relation to quality of life, is often related to the physical dimension of quality of life. This relationship was not found in this study, possibly due to the cultural context in Indonesia. Indonesian culture highly upholds the attitude of prosocial behavior, conforming to social norms and manners. The non-existent relationship between patients with high and low quality of life is probably because they belong to the same cultural background and the values of altruism they uphold.

Another difference in the findings derives in the quality of life of female patients. Several studies have shown that patients undergoing hemodialysis, especially women, tend to have a lower quality of life than men Coehlo-Marques, Wagner, \& Poli, in (Gerogianni \& Babatsikou, 2014). Women with chronic renal disease are mentioned to be more prone to depression than men. Symptoms that appear are usually feelings of sadness, anxiety, depression, low self-esteem, pessimism about the future, and lack of appetite. However, in this study, it was found that the average score of female chronic kidney disease patients was higher than that of male patients. This is possibly because many female patients are housewives or entrepreneurs, so that kidney failure does not limit physical activity or change its role in the family. 
However, lower scores on the burden of kidney disease aspect of quality of life were found in male patients. The aspect of the burden of kidney disease is self-evaluation to assess the extent to which kidney disease burdens his life psychologically (frustration, burdening the family, spending a lot of time, and disturbing life). In this study, male patients were found to have more demanding jobs to stay active. Chronic kidney disease will affect the lifestyle and role of men in the household so that it affects their evaluations of the extent to which kidney failure is a burden on their lives, hence they will tend to feel frustrated since it interferes with their lives.

This study also found some additional research data. It was found that the average quality of life in the 41-55 years group was higher than the 25-40 years group. This may be due to the support of family or partner (husband/wife/relative) as one of the supporting factors for building a better quality of life, as stated in the research of Gerogianni and Babatsikou (2014) that the social support received by patients is one of the important factors that determine patient compliance in the treatment process for chronic kidney disease. The attitude of adherence to treatment to improve the patient's quality of life (Turiano et al., 2012). Through observations, patients in this age range are accompanied by their partner or other family members. The social support received by these patients can also create a calm and a sense of security while undergoing the hemodialysis process. The presence of the family while undergoing the 5-6 hour dialysis process provides peace and comfort to the patient, even though they are not present on the bedside or inside the hemodialysis room.

Other additional data is about personality traits that are significantly related to quality of life. Neuroticism was found to be negatively associated with quality of life. However, in this study, it was further discovered that facets of neuroticism were significantly negatively correlated with aspects of quality of life, which are impulsiveness with aspects of physical and mental problems, anger hostility with aspects of the effect of kidney disease, and all facet neuroticism with aspects of symptom problems. Neuroticism is a consistent variable related to quality of life because according to Glavić et al. (2014), the main determinants of neuroticism are susceptibility to experiencing negative effects that complicate adjustment, prone to irrational ideas, decreased impulse control, ineffective coping strategies, the perception of poor control over oneself and others and the perceived lack of resources to deal with stress effectively, resulting in a low quality of life. Neuroticism gives individuals a tendency to have negative emotions, while the expression of negative emotions is one of the less effective coping strategies Shakerian, in (Amini et al., 2015; nofarast et al., 2014)

The extraversion personality trait is positively related to aspects of quality of life. In this study, it was further found that facet extraversion related to aspects of quality of life were gregariousness and assertiveness with physical and mental problems, as well as facet assertiveness and positive emotions on aspects of symptom problems. It can be explained that people who like to socialize will tend to have a better evaluation of their physical and emotional conditions that change as a result of kidney failure, thereby improving their quality of life. The ease of expressing opinions that patients with chronic kidney disease have in this trait will also increase their better judgements of their physical and emotional conditions and allow them not to be easily disturbed by the symptoms of kidney failure that appear. The positive emotions that kidney failure patients tend to have will also reduce the 
disturbances they feel due to the symptoms of kidney failure, thereby improving their quality of life. Chronic kidney disease patients, who seem to like to hang out with other patients and their caregivers, seem to enjoy the hemodialysis process more than other patients. They are more active in seeking information related to their chronic kidney disease.

This study also found that problem-focused coping, namely planful problem solving, was positively related to physical and mental problems, while seeking social support was positively related to physical and mental problems and the burden of disease. Patients who often cope with the pressure by seeking information, social support, and emotional support, have better self-evaluations on their physical and emotional changes as well as the psychological burden felt due to kidney disease thus the quality of life increases. Emotion-focused coping, which is distance and accepting responsibility, is related to the burden of disease, while positive reappraisal is related to physical and mental problems. Patients who tend to overcome problems by trying to get away from problems and directing attention to things that can lead to a positive outlook, taking responsibility for problems that arise and creating positive things, will increasingly have a better assessment of the psychological burden that may arise thereby improving their quality of life. Positive views can be created from awareness of the potential they still have so that they are motivated to have the actions or thoughts about everything positive for themselves and their environment related to what they can carry out at the time. Patients with chronic kidney disease tend to do their old hobbies or try new hobbies that are considered possible just to make them feel happier and productive.

Based on the discussion of the results in the study, it is important for patients with chronic kidney disease to recognize their personality characteristics. Several personality traits are related to the use of adaptive coping strategies so that they can cope with the stress and pressure felt as a result of chronic kidney disease and the obligation to undergo hemodialysis treatment that lasts throughout the patient's life. Positive self-evaluation and emotions are required for patients with chronic kidney disease to cope with stress more effectively and to recognize the available resources they have to manage the challenges and obstacles as a result of treatment and medications for chronic kidney disease.

\section{Conclusion}

It can be concluded that it is important for patients with chronic kidney disease to recognize their characteristics. Several traits are related to the use of adaptive coping strategies in order to manage the stress and pressure as a result of chronic kidney disease and the obligation to undergo hemodialysis treatment that lasts throughout the patient's life. Positive self-evaluation and positive emotions are essential for the patients to more effectively cope with the stress they feel and to recognize their existent self-resources to face the challenges and obstacles they felt as a result of the treatment and care for kidney failure. 


\section{Widjast \& Halim || Personality, Coping Strategy, and Quality of Life}

\section{Recommendation}

For further research, it is recommended to examine further the importance of the role of social support and ethnic differences, both from the closest relatives and other caregivers. Those are assumed to affect the perspective, stress response, and quality of life of patients with chronic kidney disease. These variables may influence the individual's ability to be creative and discover all the possibilities to improve the quality of life within chronic diseases such as kidney failure, so that individuals can be more active in using any coping strategies to manage the stress they feel.

Suggestions for the provision of psychological intervention programs to provide psychoeducation in recognizing stress symptoms, accompanied by identification of stress management processes that can be used by patients with chronic kidney disease. Information about the physical symptoms of kidney failure is also deemed necessary to help patients with kidney failure to anticipate necessary action to reduce the symptoms. The interventions may be in the form of practical ways or steps that can be taken to generate positive thoughts and emotions so as to improve the quality of life of the patients.

\section{Declarations}

\section{Acknowledgement}

Thank you to all patients who participated in the study, the hemodialysis unit, and the hospital for support and participation in this research. The authors also extend gratitude to Dr. Lidia L. Hidajat, MPH., Psikolog, Dr. Evi Sukmaningrum, M.SI., Psikolog, Agstried E. Piether, Psikolog., and dr. Dwi Karlina, SpKJ for all the support and feedback in this study. All authors contributed to the final manuscript.

\section{Funding}

This research received no specific grant from any funding agency in the public, commercial, or not-for-profit sectors

Conflict of Interests

There is no potential conflict of interest on this research

Orcid Id

Evlijn Pasha Widjast https:/ / orcid.org/0000-0003-3508-8703

Magdalena S Halim https:/ / orcid.org/0000-0003-2158-7587 


\section{References}

Amini, L., heidary maryam, m., Daneshparvar, H., \& Health, R. (2015). Personality traits and their impacts on the mental health of battered women. Journal of Midwifery and Reproductive Health, 3, 349-354.

Ana, K. B. (1999). Gangguan konsep diri, edisi 1 [self-concept disorder, first edition]. EGC.

Bakhtiari, M., Falaknazi, K., Lotfi, M., Noori, M., \& Naseri Saleh Abad, A. (2013). The relationship between personality traits, anxiety and depression, in life quality of patients under treatment by Hemodialysis [HD]. Novelty in Biomedicine, 1(1). https://doi.org/10.22037/nbm.v1i1.4575

Cellar, D. F., Voster, D., Fetters, R., Twitchell, E., Harper, G. W., \& Scott, C. (2016). Personality, coping,and well-being for people living with chronic Hepatitis C. Psychological Reports, 118(2), 649-667. https:/ / doi.org/10.1177/0033294115625557

Chan, Y., Naujoks, D., Huen, D., Russell, S., Chan, Y., Naujoks, D., Huen, D., \& Russell, S. (2011). Insect population control by homing endonuclease-based gene drive: An evaluation in drosophila melanogaster. Genetics, 188(1).

Folkman, S., \& Lazarus, R. S. (1985). If it changes it must be a process: Study of emotion and coping during three stages of a college examination. Journal of Personality and Social Psychology, 48(1), 150-170. https: / / doi.org/10.1037/0022-3514.48.1.150

Gerogianni, S. K., \& Babatsikou, F. P. (2014). Psychological aspects in chronic renal failure. Health Science Journal, 8(2), 205-214.

Glavić, Z., Galić, S., \& Krip, M. (2014). Quality of life and personality traits in patients with colorectal cancer. Psychiatria Danubina, 26(2), 172-180.

Halim, M. S., Derksen, J. J. L., \& van der Staak, C. P. F. (2004). Development of the revised neo personality inventory for Indonesia: A preliminary study. In In b. n. setiadi, a. supratiknya, w. j. lonner, $\mathcal{E} y$. h. poortinga (eds.), ongoing themes in psychology and culture:proceedings from the 16th international congress of the international association for cross-cultural psychology. International Association for Cross-Cultural Psychology. https: / / scholarworks.gvsu.edu / iaccp_papers / 242

Hays, R., Gibori, G., \& Bejsovec, A. (1997). Wingless signaling generates pattern through two distinct mechanisms. Development, 124(19).

Mailani, F. (2015). Kualitas hidup pasien penyakit ginjal kronik yang menjalani Hemodialisis : Systematic review [Quality of life of patients with chronic kidney disease undergoing Hemodialysis: A systematic review]. Ners Jurnal Keperawatan, 11(1), 1-8.

Marques, J. P. C. (2014). Closed versus open innovation: Evolution or combination? International Journal of Business and Management, 9(3). https://doi.org/10.5539/ijbm.v9n3p196

Niven, N. (2002). Psikologi kesehatan [health psychology]. Jakarta, EGC.

nofarast, M. G., Sherbaf, H., \& Yaghoubi, A. (2014). Comparing the effect of quality of life, psychological stressors and coping strategies in kidney patients and normal people. European Online Journal of Natural and Social Sciences, 3, 436-444. 
Poppe, C., Crombez, G., Hanoulle, I., Vogelaers, D., \& Petrovic, M. (2012). Improving quality of life in patients with chronic kidney disease: Influence of acceptance and personality. Nephrology Dialysis Transplantation, 28(1), 116-121. https://doi.org/10.1093/ndt/gfs151

Priyanti, D., \& Farhana, N. (2016). Perbedaan kualitas hidup pasien gagal ginjal yang bekerja dan tidak bekerja yang menjalani Hemodialisis di yayasan ginjal diatrans Indonesia [differences in the quality of life of working and non-working kidney failure patients undergoing Hemodialysis at the Indonesian diatrans kidney foundation]. INQUIRY Jurnal Ilmiah Psikologi, 7(1), 41-47.

Roberts, B. W., Walton, K. E., \& Bogg, T. (2005). Conscientiousness and health across the life course. Review of General Psychology, 9(2), 156-168. https: / / doi.org/10.1037/1089-2680.9.2.156

Sarafino, E. P. (2008). Health psychology: Biopsychosocial interactions sixth edition. USA: The College of New Jersey, Mc Graw Hill.

Sarafino, E. P., \& Smith, T. W. (2012). Health psychology: Biopsychosocial interaction 7th edition. New York; John Wiley \& Sons, Inc.

Saswita, D., \& Bayhakki., H. (2015). Hubungan antara tingkat kecemasan dengan strategi koping pasien gagal ginjal kronik yang menjalani Hemodialisis [The relationship between anxiety levels and coping strategies in chronic renal failure patients undergoing Hemodialysis]. JOM PSIK, 2(2), 1014-1023.

Steel, P., Schmidt, J., \& Shultz, J. (2008). Refining the relationship between personality and subjective well-being. Psychological Bulletin, 134(1), 138-161.

Turiano, N. A., Pitzer, L., Armour, C., Karlamangla, A., Ryff, C. D., \& Mroczek, D. K. (2012). Personality trait level and change as predictors of health outcomes: Findings from a national study of Americans (MIDUS). The Journals of Gerontology, 67(1), 4-12. https:/ / doi.org/10.1093/geronb/ gbr072

van Straten, A., Cuijpers, P., van Zuuren, F. J., Smits, N., \& Donker, M. (2006). Personality traits and health-related quality of life in patients with mood and anxiety disorders. Quality of Life Research, 16(1). https:/ / doi.org/10.1007/s11136-006-9124-x 